\title{
Variation of adult admission and co-morbidity to general intensive care unit of BSMMU: Impact on outcome
}

\author{
Labib Imran Faruque1, Qumrul Huda², Debasish Banik² and A.K.M. Shafiqur Rahman² \\ ${ }^{1}$ International Center for Diarrheal Disease Research, Bangladesh (ICDDR,B). \\ 2Dept. of Anesthesia, Bangabandhu Sheikh Mujib Medical University, Shahbag, Dhaka.
}

Address for Correspondence

Dr. Labib Imran faruque, Research fellow, PIDVS, HSID. ICDDRB

E-mail : labibimran@yahoo.com

\begin{abstract}
A retrospective study was done in ICU of BSMMU during January to June 2007 with a total number of 157 patients. Patients were included from this hospital and also from private hospitals. In accordance of the criteria for analysis a structured questionnaire was used whereas data obtain from hospital record sheets and file.

We observed admission diagnosis, co-morbidities, length of stay, different procedures and overall outcome. Among 157 Patients age group of $61-70$ yrs. constitutes the major proportion, which was $20.4 \%$ and male was $61.8 \%$. 108 patients (75.2\%) were admitted due medical illness and among which respiratory failure was $15.3 \%$, intracranial hemorrhage was 13.4\%. Among 112 deaths 77 died after 96 hours of admission. Death occurred in $90.5 \%$ for non-traumatic hemorrhage and $94.1 \%$ cases for pneumonia $(\mathrm{P}<0.5)$. We did not find any significant association between outcome and co-morbidities except for cerebrovascular in sufficiency $(\mathrm{P}<0.5)$. Therefore we can predict that admission diagnosis and other factors
\end{abstract}

\section{Introduction}

A major proportion of admissions to adult intensive care units (ICUs) in the developed countries are patients with medical problems. ${ }^{1}$ Besides the effects of demographic factors and co-morbid illness on outcomes of critical illness have been studied. 2,3 Medical patients suffer a higher mortality, both during their ICU admission and during the remainder of their hospital stay. ${ }^{4}$ Medical patients are at higher risk of hospital mortality ( $23 \%$ vs. $14 \%$ for operative admissions) because of their greater severity of illness in terms of acute physiological derangement and admission diagnosis. ${ }^{5}$ However, the intermediate survival of medical patients is also poor; the median survival of over 300 medical patients in Norwich has been reported as 40 days. ${ }^{6}$

Intensive care unit is expensive and scarce in worldwide including Bangladesh. ${ }^{7}$ Total number of ICU bed in Bangladesh is about 190 for 150 million peoples. Therefore admission in intensive care unit (ICU) should get priority, so that patients are likely to get benefit from ICU care. ${ }^{8}$ This restriction excludes patients whose death is inevitable as well as those patients who should survive and do well without the need for intensive care. The working practices and outcomes from intensive care units are poorly documented in our country. The patients were admitted in the Intensive care unit from discipline of Bangabandhu Sheikh Medical University hospital and also referred from other hospitals.
This study was instituted to investigate retrospective review of stored data from the archive. Demographic details, referral source, admission time, admission diagnosis, co-morbidities and outcome were recorded to provide data for future development of Intensive Care Facilities.

\section{Materials \& methods}

We studied retrospectively 157 patients admitted to General Intensive care unit of Bangabandhu Sheikh Mujib Medical University Hospital in the year 2007 from January to June. Ethical clearance was taken from the departmental Ethical Committee of the Department of Anaesthesia, Analgesia and Intensive Care Medicine, BSMMU. Patients were admitted from the general medicine and surgical ward and emergency department. Patients developing a medical problem following surgery and patients admitted under the care of surgical specialties and did not need surgery were also included in the study.

In accordance of the criteria for analysis, a structured questionnaire was used whereas data obtained from admission register, patient follow-up sheets, mortality record books and also from patients admission files. We observed admission diagnosis, co-morbidities, length of stay, different procedures and overall outcomes. We divided the total patients in different age groups. We also studied patients of different speciality referred to the ICU. We also observed relationship of mortality with admission diagnosis. We categorized the patients as recovery and death and their relation with admission diagnosis and co-morbidities. 
Summary statistics are given as means for normally distributed data. Association in distribution was examined using Chi-square test. A p-value of 0.05 was considered statistically significant. SPSS 11.5 was used for data entry and analysis and Endnote $\mathrm{X}$ for creating reference library.

\section{Results}

A total of 157 admissions with complete records were available. It was observed that the highest concentration of the population was in age group 61-70 years which was $20.4 \%$ of total ICU admission and second highest was in age group 51-60 years which was 19.7\%. Among 157 patients, 60 were found female which was $38.2 \%$ and 97 were male, 61.8 in percentage. It is not exactly same distribution of national average of sex.



Figure 1: Composition of referring unit

The investigators identified that 152 cases were admitted as an emergency cases which was 97 percent. Of all admissions, medical ground was for 118 patients which in percentage was $75.2 \%$. Surgical cases were 25 in numbers among which scheduled cases and emergency cases were 14 in numbers. In this government hospital ICU $36.3 \%$ admission occurred from other ICU and $16.6 \%$ other hospitals.

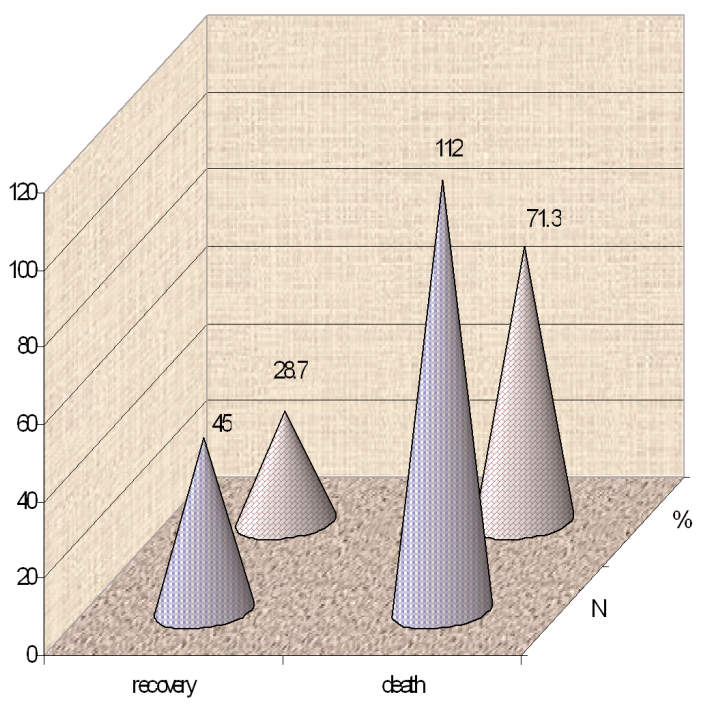

Figure 2 : Medical Outcomes

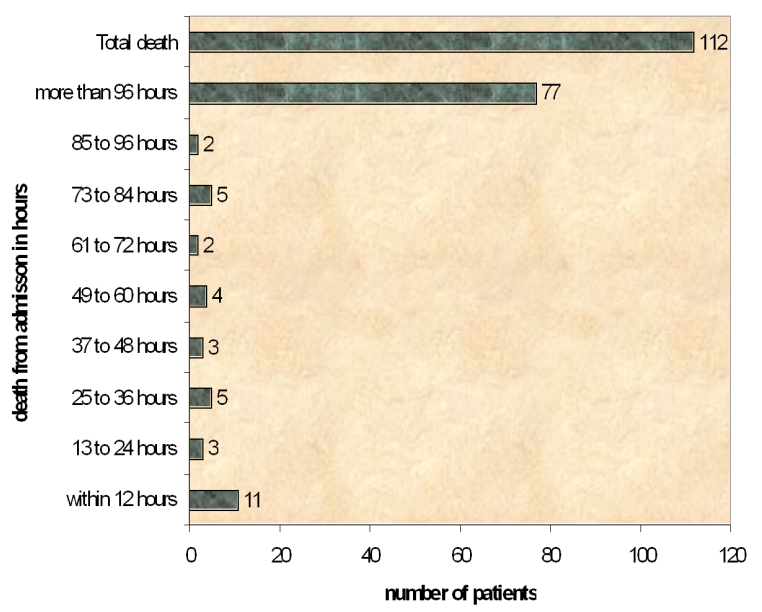

Figure 3: Time of death from admission

Out of 157 patients, 45 patients recovered from their illness with partial or complete disability which was 28.7 in percentage. But substantial number of patients (112) died which was 71.3 percent. It is important to note that no patient took Discharge on Risk Bond (DORB) from their hospital. Figure 3 shows that among 112 died patients 77 patients died after 96 hours of ICU admission which was 49.0 in percent.

Table I : Relationship of admission diagnosis with medical outcomes

\begin{tabular}{|c|c|c|c|c|}
\hline \multirow{2}{*}{$\begin{array}{l}\text { ICU admission } \\
\text { diagnosis }\end{array}$} & \multicolumn{2}{|c|}{ Outcome } & \multirow{2}{*}{ Total } & \multirow{2}{*}{$P$ value } \\
\hline & Recovery & Death & & \\
\hline multiple trauma & $5(62.5 \%)$ & $3(37.5)$ & $8(100 \%)$ & $0.0298^{*}$ \\
\hline $\begin{array}{l}\text { major abdominal } \\
\text { surgery }\end{array}$ & $7(63.6 \%)$ & $4(36.4)$ & $11(100 \%)$ & $0.0078^{*}$ \\
\hline ischaemic stroke & $1(9.1 \%)$ & $10(90.9)$ & $11(100 \%)$ & $0.1365 \mathrm{NS}$ \\
\hline $\begin{array}{l}\text { chronic obstructive } \\
\text { pulmonary disease }\end{array}$ & $1(14.3 \%)$ & $6(85.7)$ & $7(100 \%)$ & $0.3894 \mathrm{NS}$ \\
\hline $\begin{array}{l}\text { non traumatic } \\
\text { intracranial } \\
\text { haemorrhage }\end{array}$ & $2(9.5 \%)$ & $19(90.5)$ & $21(100 \%)$ & $0.0371^{*}$ \\
\hline $\begin{array}{l}\text { respiratory } \\
\text { distress-pneumonia }\end{array}$ & $1(5.9 \%)$ & $16(94.1)$ & $17(100 \%)$ & $0.0278^{*}$ \\
\hline brain tumour & $5(55.6 \%)$ & $4(44.4)$ & $9(100 \%)$ & $0.0661 \mathrm{NS}$ \\
\hline Hypotension & $2(40.0 \%)$ & $3(60.0)$ & $5(100 \%)$ & $0.5688 \mathrm{NS}$ \\
\hline Others & $18(40.9 \%)$ & $26(59.1)$ & $44(100 \%)$ & $0.0342^{*}$ \\
\hline respiratory failure & $3(12.5 \%)$ & $21(87.5)$ & $24(100 \%)$ & $0.0571 \mathrm{NS}$ \\
\hline
\end{tabular}

*Significant NS- Not Significant

Non-traumatic intracranial haemorrhage was the most common diagnosis $(n=21)$ which was followed by Pneumonia $(\mathrm{n}=17)$. Death occurred in $90.5 \%$ and $94.1 \%$ cases respectively where as $p$ value were 0.0371 and 0.0278 . Among 45 patients, highest recovery were from major abdominal surgery $(n=7$ and $P$ value 0.0078$)$ followed by multiple trauma ( $\mathrm{n}=5$ and $\mathrm{P}$ value 0.0298 ). No cases were transferred to other hospitals. Among 112 death cases, intracranial haemorrhage, pneumonia, respiratory failure contributed the major proportion. 
Table II : Co morbidities with outcome

\begin{tabular}{|c|c|c|c|c|}
\hline \multirow{2}{*}{ Co morbidities } & \multicolumn{2}{|c|}{ Outcomes } & \multirow[b]{2}{*}{ Total } & \multirow[b]{2}{*}{ P value } \\
\hline & Recovery & Death & & \\
\hline Diabetes (DM) & $3(20 \%)$ & $12(80.0)$ & $15(100.0)$ & $0.4353 \mathrm{NS}$ \\
\hline $\begin{array}{l}\text { arterial hypertensio } \\
\text { (HTN) }\end{array}$ & $\mathrm{n}_{5(25}$ & $15(75.0)$ & $20(100.0)$ & $0.6981 \mathrm{NS}$ \\
\hline $\mathrm{DM}+\mathrm{HTN}$ & $4(18.2 \%)$ & $18(81.8)$ & $22(100.0)$ & $0.2410 \mathrm{NS}$ \\
\hline HTN + coronary disease & $2(16.7 \%)$ & $10(83.3)$ & $12(100.0)$ & $0.3389 \mathrm{NS}$ \\
\hline $\begin{array}{l}\mathrm{DM}+\mathrm{HTN}+\text { coronan } \\
\text { disease }\end{array}$ & $y_{3}(16$ & $15(83.3)$ & $18(100.0)$ & $0.2316 \mathrm{NS}$ \\
\hline $\begin{array}{l}\text { chronic obstructiv } \\
\text { airway disease }\end{array}$ & $e_{4(19 \%)}$ & $17(81.0)$ & $21(100.0)$ & $0.2951 \mathrm{NS}$ \\
\hline chronic renal failure & $2(22.2 \%)$ & $7(77.8)$ & $9(100.0)$ & $0.6598 \mathrm{NS}$ \\
\hline $\begin{array}{l}\text { chronic renal failur } \\
\text { with haemodialysis }\end{array}$ & $e_{1(20 \%)}$ & $4(80.0)$ & $5(100.0)$ & $0.6633 \mathrm{NS}$ \\
\hline malignant disease & $7(36.8 \%)$ & $12(63.2)$ & $19(100.0)$ & $0.4003 \mathrm{NS}$ \\
\hline $\begin{array}{l}\text { cerebro-vascular } \\
\text { insufficiency }\end{array}$ & $3(11.1 \%)$ & $24(88.9)$ & $27(100.0)$ & $0.0266^{*}$ \\
\hline
\end{tabular}

* significant NS- not significant

In case of co-morbidities, 22 patients suffered from diabetes and hypertension whereas 4 cases recovered from the disease and 18 patients were died. Twenty patients suffered from arterial hypertension whereas 5 cases recovered from the disease and 15 people died. Among 21 cases of chronic obstructive airway disease $81 \%$ died (P value 0.2951 ) and 27 cases of cerebrovascular insufficiency $88.9 \%$ patients died ( $\mathrm{P}$ value 0.0266).

\section{Discussion}

Our analysis was based on total number of ICU admission for the time period of six months. The data were gathered as a collaborative clinical ICU survey. The method of data collection, training and data validation was designed to minimize errors. However, the information was likely to be most accurate for objective information, such as patient location before ICU admission, admission diagnosis and co-morbidities and mortality rates, which were used to support the main themes of this article.

In our country, by the time patients reach the ICU, it may be possible to identify those with a high risk of death but it may be too late to do much to influence the outcome of those who die within the first day or two days of admission. Such patients include those patients with brain damage after trauma or anoxia, with terminal cancer, and end stage respiratory failure. Many of these patients will have had underlying pathology and physiology too deranged to respond to a short period of intensive care therapy. Much intensive care research is focused on treatments directed at sepsis, adult respiratory distress syndrome, and multiple organ failure, problems that occur primarily in the long stay ICU patient. To appreciably decrease early ICU mortality, it may be necessary to intervene before ICU admission.

In our study among 157 patients, age group of 61-70 years constitutes the major proportion which was $20.4 \%$ and Male was 61.8 in percentage. One hundred and eighteen patients $(75.2 \%)$ were admitted due to medical diagnosis among which respiratory failure was 15.3 in percentage and intracranial hemorrhage was 13.4 in percentage. Among 112 deaths 77 patients died after 96 hours of ICU admission. Death occurred in $90.5 \%$ for non-traumatic intracranial haemorrhage and $94.1 \%$ cases for pneumonia $(\mathrm{p}<.05)$.

Fewer early deaths among emergency patients in the ICU are consistent with the other studies. ${ }^{9}$ In a study it is shown that patients from the general wards with a higher mortality of $53.2 \%$ in comparison to $29.8 \%$ admitted from Emergency Unit and ICU mortality of critically ill medical patients is also high $(28.4 \%) .{ }^{4}$ Our findings correlates with the findings that with increasing age ICU admission and utilization rates are proportionately increased in the recent years. ${ }^{10,11}$ ICU admission also increased significantly with an increasing number of co morbid conditions among which Cardiovascular diseases, hemiplegia, and severe renal, severe liver, and ulcer diseases were notable. ${ }^{10} \mathrm{We}$ did not find any significant association between outcome and co morbidities except for cerebrovascular insufficiency ( $\mathrm{P}$ value $<.05$ ). Therefore we can predict that admission diagnosis and other factors might play a vital role altogether in the outcomes of patients.

Prospective study would allow us a detailed exploration of the effect of clinical influences on the outcomes of critically ill patients. Another limitation was inconstancy of laboratory procedure and other parameter from the ICU and from regular departments. This study included small numbers of critically ill patients identified.

There is a golden hour for critically ill patients so early efforts should be made available. Remote monitoring round the clock for remote management of ICU patients by critical care specialists is highly demanded for decreased mortality, incidence of complications, and length of stay. The socio-demographic changes lead to a significantly increased demand for ICU services in Bangladesh.

\section{References}

1. Rowan, K.M., et. al., Intensive Care Society's APACHE II study in Britain and Ireland : Variations in case mix of adult admissions to general intensive care units and impact on outcome. British Medical Journal, 1993. 307: 972-7. 
2. Zilberberg, M.D. and S.K. Epstein, Acute lung injury in the medical ICU: Comorbid conditions, age, etiology, and hospital outcome. Am J Respir Crit Care Med, 1998. 157: 1159-64.

3. Angus, D.C., W.T. Linde-Zwirble, and J. Lidicker, Epidemiology of severe sepsis in the United States: Analysis of incidence, outcome, and associated costs of care Crit Care Med, 2001. 29: 1303-10.

4. Trivedi, M. and S.A. Ridley, Intermediate outcome of medical patients after intensive care. Anaesthesia, 2001. 56: 841-46.

5. Intensive Care National Audit and Research Centre, Data Analysis from the Case Mix Program Database. 2000(5).

6. Lam, S. and S. Ridley, Critically ill medical patients, their demographics and outcome. Anaesthesia, 1999. 54: 845-52.

7. Ryan, D.W., Providing intensive care. British Medical Journal, 1996. 312: 654.

8. Jennett, B., Inappropriate use of intensive care. British Medical Journal, 1984. 289: 1709-11.

9. Elisheva, S., et al., Survival of critically ill patients hospitalized in and out of intensive care. Crit Care Med, 2007. 35(2) : 449-57.

10. Seferian, E.G. and B. Afessa, Demographic and clinical variation of adult intensive care unit utilization from a geographically defined population. Crit Care Med, 2006. 34( 8) :2113-19

11. Boumendil, A., et al., Should elderly patients be admitted to the intensive care unit? Intensive Care Med 2007. 33: 1252-62. 